\title{
Application of Brusov-Filatova-Orekhova Theory (BFO Theory) and Modigliani-Miller Theory (MM Theory) in Rating
}

\author{
P. N. Brusov ${ }^{*}$, T. V. Filatova ${ }^{2}$, N. P. Orekhova ${ }^{3}$, V. L. Kulik ${ }^{4}$ \\ ${ }^{1}$ Department of Data Analysis, Decision Making, and Financial Technology, Financial University under the Government of \\ Russian Federation, Moscow, Russia \\ ${ }^{2}$ Department of Corporate Finance and Corporate Governance, Financial University under the Government of Russian \\ Federation, Moscow, Russia \\ ${ }^{3}$ High Business School, Southern Federal University, Rostov-on-Don, Russia \\ ${ }^{4}$ Department of Management, Financial University under the Government of Russian Federation, Moscow, Russia \\ Email: *pnb1983@yahoo.com
}

How to cite this paper: Brusov, P.N., Filatova, T.V., Orekhova, N.P. and Kulik, V.L. (2018) Application of Brusov-FilatovaOrekhova Theory (BFO Theory) and Modigliani-Miller Theory (MM Theory) in Rating. Theoretical Economics Letters, 8, 866887. https://doi.org/10.4236/tel.2018.85062

Received: February 19, 2018

Accepted: April 6, 2018

Published: April 9, 2018

Copyright $\odot 2018$ by authors and Scientific Research Publishing Inc. This work is licensed under the Creative Commons Attribution International License (CC BY 4.0).

http://creativecommons.org/licenses/by/4.0/

\begin{abstract}
The paper is devoted to application of Brusov-Filatova-Orekhova theory (BFO theory) and Modigliani-Miller theory (MM theory) in rating. A serious modification of both theories in order to use them in rating procedure has been required. The financial "ratios" (main rating parameters) were introduced into both these theories. The necessity of an appropriate use of financial flows discounting in rating methodologies is discussed. The dependence of the weighted average cost of capital (WACC), which plays the role of discount rate, on coverage and leverage ratios is analyzed. The use of BFO theory allows applying obtained results for real economics, for companies with finite lifetime, introduce a factor of time into theory, estimate the creditworthiness of companies of arbitrary lifetime (or arbitrary age), introduce the financial flows discounting, using the correct discount rate etc. Obtained results made possible to use the power of these theories in the rating and create a new base for rating methodologies, by other words this allows develop a new approach to methodology of rating, requiring a serious modification of existing rating methodologies. The article is organized as follows: In Section 2, we modify for the first time the Modigliani-Miller theory (perpetuity limit of BFO theory) for rating needs and introduce the financial "ratios" (a direct and inverse) into this theory. As well we analyze here the dependence of company's weighted average cost of capital (WACC) on the coverage ratios and on the leverage ones. In Section 3, we discuss the method of evaluation of the discount rate with using one or a few financial "ratios". In Section 4, the conclusions con-
\end{abstract}


cerning the application of perpetuity limit of the modern theory of capital structure-BFO theory (MM theory) in rating have been done. In Section 5, we modify for the first time the general version of BFO theory (for companies of arbitrary age) for rating needs and introduce the financial "ratios" (a direct and inverse) into this theory. Here we as well analyze the dependence of company's weighted average cost of capital (WACC) on the coverage ratios and on the leverage ones. We make calculations for two company ages (three and five years) in order to demonstrate that developed approach could be applied for companies of arbitrary age and to have a possibility to compare results for companies of different ages. Section 6 is devoted to conclusions made by the analysis of obtained results. Application of developed methods to rating is discussed here as well as completely new horizons which are opening in the rating industry via this investigation.

\section{Keywords}

Brusov-Filatova-Orekhova Theory, Modigliani-Miller Theory, Rating, Rating Methodology, Coverage Ratios, Leverage Ratios, Discounting of Financial Flows, Discount Rate

\section{Introduction}

While the role of rating agencies in economics is very important (generated by them credit ratings of issuers help to investors make reasonable investment decision, help issuers with good enough ratings get credits on lower rates etc.) there are a lot of shortcomings in their activity.

Among them:

1) Closeness of rating agencies,

2) A failure or a very narrow use of discounting of financial flows (even in those rare cases where it is used, it is used with the incorrect discount rate),

3) The existing accounting of industry specifics of issuer is clearly insufficient,

4) Accounting of the particularities of the issuer, features of financial reports, taxation, legal and financial system is neglected in favor of achieving full comparability of financial reports,

5) Some financial ratios define ambiguously the state of the issuer,

6) Possibility of a formal hit of individual characteristics of factor/subfactor simultaneously in several categories of evaluation, particularly for qualitative factors, in this case, the score is based on expert opinion,

7) The formalization of expert opinions, which is one of the most important tasks in improving of the rating methodology, is far from its solution,

8) etc.

In this paper, we develop a new approach to rating methodology introducing an appropriate discounting of financial flows, describing the method of evaluation of the correct discount rate when discounting financial flows, introducing 
the financial "ratios" (main rating parameters) into modern theory of capital cost and capital structure-BFO theory [1]-[16] — and its perpetuity limit-MM theory [17] [18] [19] — and using the power of these theories in the rating methodology. As well we study the dependence of company's weighted average cost of capital, $W A C C$, on the financial ratios, which allow evaluate the correct discount rate with accounting of the financial ratios.

The account of the time factor in terms of discounting is obvious, because it is connected with the time value of money. The financial part of the rating assessment of creditworthiness of issuers is based on a comparison of generated income with the value of the debt and the interest payable. Because income and disbursement of debt and interest are separated in time, the use of discounting when comparing revenues with the value of debt and interest is absolutely necessary for assigning credit ratings for issuers.

This raises the question about the value of discount rate. This question has always been one of the major and extremely difficult in many areas of finance: corporate finance, investment, it is particularly important in business valuation, where a slight change in the discount rate leads to a significant change in the assessment of company capitalization, that is used by unscrupulous appraisers for artificial bankruptcy of the company. And the value of discount rate is extremely essential as well in rating. And there is only one theory, which allow evaluate the correct discount rates (the weighted average cost of capital WACC and equity cost of capital $k_{e}$ ) - the modern theory of capital structure by Brusov-FilatovaOrekhova [1]-[16]. But we start from its perpetuity limit-Modigliani-Miller theory [17] [18] [19] for simplicity.

The main contributions of this paper is the application of Brusov-FilatovaOrekhova theory (BFO theory) [1]-[16] and Modigliani-Miller theory (MM theory) [17] [18] [19] in rating. A serious modification of both theories for rating procedure has been required. For the first time the introduction of the financial "ratios" (a direct and inverse) into these theories has been done. As well we study the dependence of company's weighted average cost of capital (WACC) on the coverage ratios and on the leverage ones. The use of BFO theory allows applying obtained results for real economics, where all companies have finite lifetime, introduce a factor of time into theory, estimate the creditworthiness of companies of arbitrary age (or arbitrary lifetime), introduce discounting of the financial flows, using the correct discount rate etc. Use of the tools of well developed theories in rating opens completely new horizons in the rating industry, which could go from the mainly use of qualitative methods of the evaluation of the creditworthiness of issuers to a predominantly quantitative evaluation methods that will certainly enhance the quality and correctness of the rating.

\section{Modification of Modigliani-Miller Theory for Rating Needs}

The financial "ratios", constitute a direct and inverse ratios of various generated cash flows to debt values and interest ones, play quite significant role in quanti- 
fication of the creditworthiness of the issuers. The examples of such ratios are as following: DCF/Debt, FFO/Debt, CFO/Debt, FOCF/Debt, FFO/cash interest, EBITDA/interest, Interests/EBITDA, Debt/EBITDA and some others.

We introduce these financial "ratios" into the perpetuity limit of modern theory of capital structure-BFO theory and then into the general version of BFO theory (for companies of arbitrary age). This is quite important because allows use this theory as a powerful tools when discounting of financial flows using the correct discounting rate in rating.

This has required the modification of the BFO theory and its perpetuity limit - Modigliani-Miller theory. The needs of modification is connected to the fact that used in financial management the concept of "leverage" as the ratio of debt value to the equity value substantially differs from the concept of "leverage" in the rating, where it is understood as ratio of the debt value to the generated cash flow values (income, profit, etc.).

Modigliani-Miller theory with corporate taxes [17] [18] [19] shows that capitalization of financially dependent (leveraged) company, $V_{L}$, is equal to the capitalization of financially independent (unleveraged) company, $V_{0}$, increased by the size of the tax shield for perpetuity time, $D t$,

$$
V_{L}=V_{0}+D t .
$$

Substituting the expressions for both capitalizations, one has

$$
\frac{C F}{W A C C}=\frac{C F}{k_{0}}+D t
$$

Let us now introduce the parameters, using in ratings, into Modigliani-Miller theory, which represents a perpetuity limit of modern theory of capital structure by Brusov-Filatova-Orekhovatheory (BFO theory) [1]-[16].

Two kind of financial ratios will be considered: coverage ratios and leverage ratios.

We will start from the coverage ratios.

\subsection{Coverage Ratios}

We will consider three kind of coverage ratios: coverage ratio of debt, coverage ratio of interest on the credit and coverage ratio of debt and interest on the credit.

\subsubsection{Coverage Ratios of Debt}

Let us consider first the coverage ratios of debt $i_{1}=C F / D$.

Dividing both parts of Equation (2) by Done gets

$$
\begin{aligned}
& \frac{i_{1}}{W A C C}=\frac{i_{1}}{k_{0}}+t \\
& W A C C=\frac{i_{1} k_{0}}{i_{1}+t k_{0}}
\end{aligned}
$$

The coverage ratio of debt $i_{1}=C F / D$ could be used for assessment of the following rating ratios: DCF/Debt, FFO/Debt, $\mathrm{CFO} /$ Debt, FOCF/Debt and some 
others. Formula (3) will be used to find a dependence $W A C C\left(i_{1}\right)$.

\subsubsection{Coverage Ratios of Interest on the Credit}

Consider now coverage ratio of interest on the credit $i_{2}=C F / k_{d} D$.

By use of the Modigliani-Miller theory for case with corporate taxes

$$
V_{L}=V_{0}+D t,
$$

one could derive the expression for $W A C C\left(i_{2}\right)$

$$
\begin{aligned}
& \frac{C F}{W A C C}=\frac{C F}{k_{0}}+D t \\
& \frac{i_{2}}{W A C C}=\frac{i_{2}}{k_{0}}+\frac{i_{2}}{k_{d}} \\
& W A C C=\frac{i_{2} k_{0} k_{d}}{i_{2} k_{d}+t k_{0}}
\end{aligned}
$$

This ratio $\left(i_{2}\right)$ could be used for assessment of the following parameters, used in rating, FFO/cash interest, EBITDA/interest and some others. Formula (4) will be used to find a dependence $W A C C\left(i_{2}\right)$.

\subsubsection{Coverage Ratios of Debt and Interest on the Credit}

Below we consider the coverage ratios of debt and interest on the credit simultaneously $i_{3}=\frac{C F}{D\left(1+k_{d}\right)}$. This is a new value, introduced by us here for the first time. Using the Modigliani-Miller theory for case with corporate taxes

$$
V_{L}=V_{0}+D t
$$

we get the dependence $W A C C\left(i_{3}\right)$

$$
\begin{aligned}
& \frac{C F}{W A C C}=\frac{C F}{k_{0}}+D t \\
& \frac{i_{3}}{W A C C}=\frac{i_{3}}{k_{0}}+\frac{t}{1+k_{d}} \\
& W A C C=\frac{i_{3} k_{0}\left(1+k_{d}\right)}{i_{3}\left(1+k_{d}\right)+t k_{0}}
\end{aligned}
$$

This ratio $\left(i_{3}\right)$ could be used for assessment of the following rating ratios: FFO/Debt + interest, EBITDA/Debt + interest and some others. Formula (5) will be used to find a dependence $W A C C\left(i_{3}\right)$.

Let us analyze the dependence of company's weighted average cost of capital ( WACC) on the coverage ratios on debt $i_{1}$, on interest on the credit $i_{2}$ and on coverage ratios on debt and interest on the credit with the following data: $k_{0}=$ $12 \% ; k_{d}=6 \% ; t=20 \% ; i_{j}$ run from 0 up to 10 . Results are presented at Figure 1.

The dependence of company's weighted average cost of capital (WACC) on the coverage ratio on debt and interest on the credit $i_{2}$ is presented at Figure 3.

The dependence of company's weighted average cost of capital (WACC) on the coverage ratio on debt $i_{1}$, on interest on the credit $i_{2}$, and on debt and interest 
on the credit $i_{3}$ is presented at Figure 4.

It is seen from the Figures 1-4 that $W A C C\left(i_{j}\right)$ is increasing function on $i_{j}$ with saturation around $i_{j}$ value of order 1 for ratios $i_{1}$ and $i_{3}$ and of order 4 or 5 for ratios $i_{2}$. At saturation $W A C C$ reaches the value $k_{0}$ (equity value at zero leverage level). This means that for high values of $i_{j}$ one can choose $k_{0}$ as a discount rate with a good accuracy. Thus the role of parameter $k_{0}$ increases drastically. The method of determination of parameter $k_{0}$ has been developed by Anastasiya Brusova [14]. So, parameter $k_{0}$ is the discount rate for limit case of high values of $i_{j}$

\subsection{Leverage Ratios}

We will consider now the leverage ratios. Three kind of leverage ratios will be considered: leverage ratios of debt, leverage ratios of interest on the credit and leverage ratios of debt and interest on the credit.

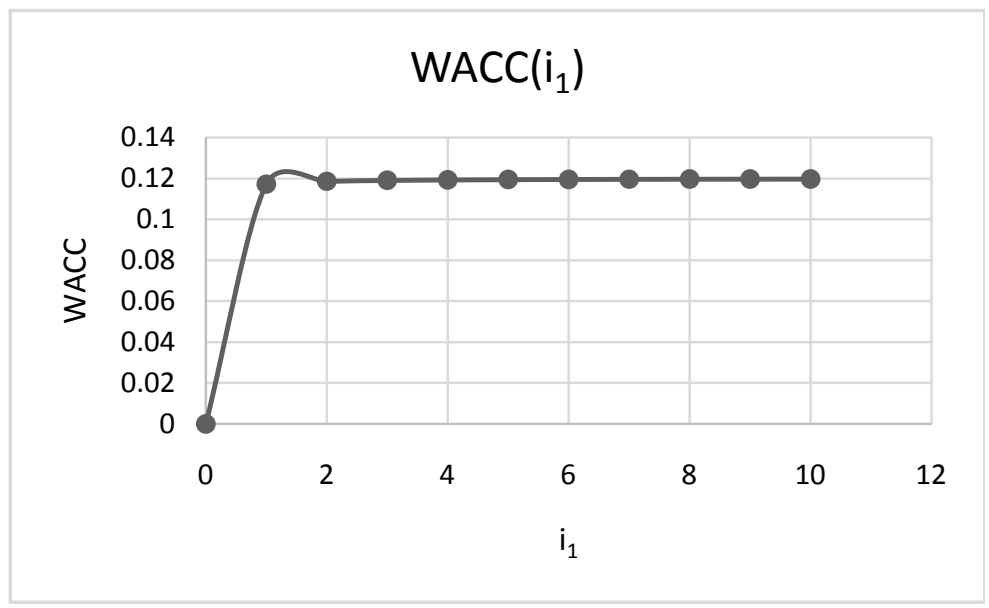

Figure 1. The dependence of company's weighted average cost of capital (WACC) on the coverage ratio on debt $i_{1}$.

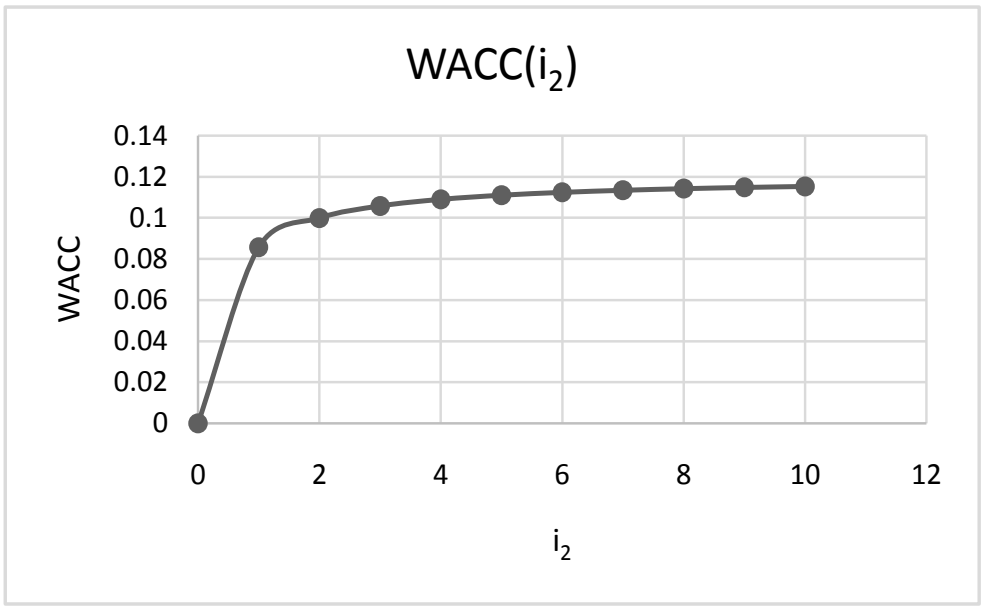

Figure 2. The dependence of company's weighted average cost of capital (WACC) on the coverage ratio on interest on the credit $i_{2}$. 


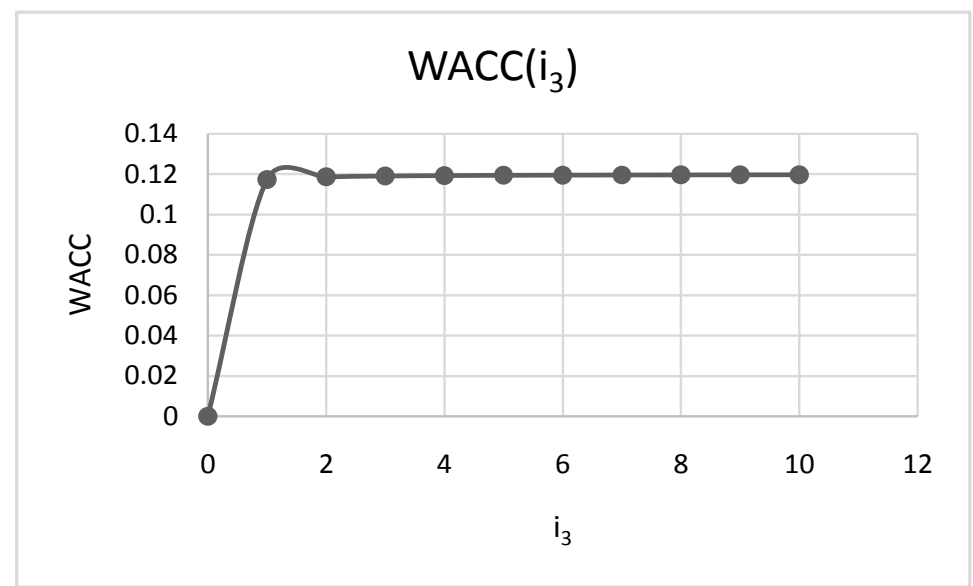

Figure 3. The dependence of company's weighted average cost of capital (WACC) on the coverage ratio on debt and interest on the credit $i_{3}$.

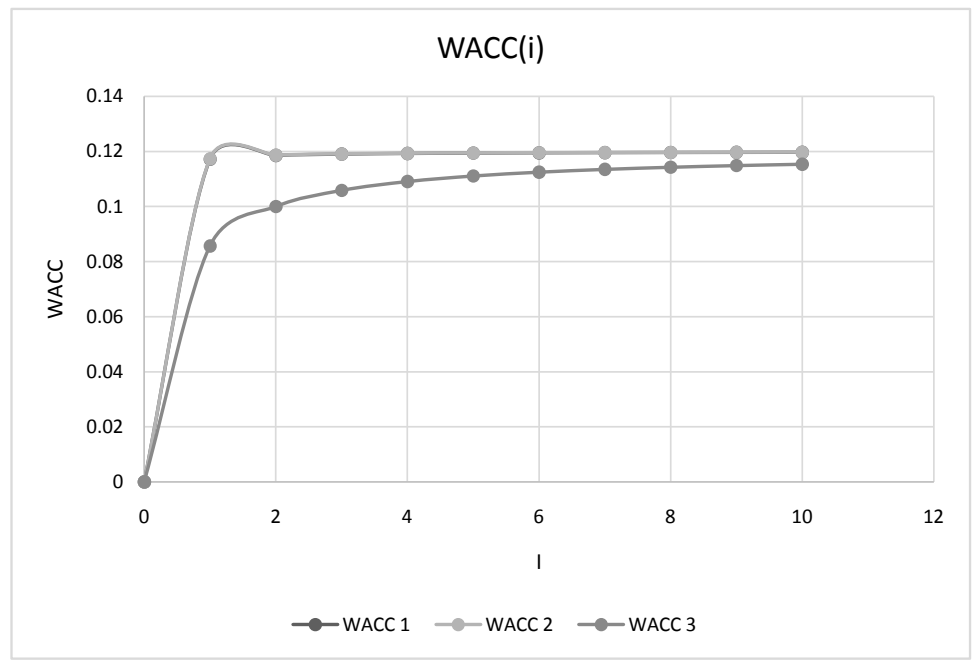

Figure 4. The dependence of company's weighted average cost of capital (WACC) on the coverage ratio on debt $i_{1}$, on interest on the credit $i_{2}$, and on debt and interest on the credit $i_{3}$.

\subsubsection{Leverage Ratios for Debt}

$$
\text { Here } l_{1}=D / C F
$$

As above for coverage ratios we use the Modigliani-Miller theorem for case with corporate taxes

$$
V_{L}=V_{0}+D t,
$$

we derive the expression for $W A C C\left(l_{1}\right)$

$$
\begin{aligned}
\frac{C F}{W A C C} & =\frac{C F}{k_{0}}+D t \\
\frac{1}{W A C C} & =\frac{1}{k_{0}}+l_{1} t \\
W A C C & =\frac{k_{0}}{1+t l_{1} k_{0}}
\end{aligned}
$$


This ratio $\left(l_{1}\right)$ can be used to assess of the following parameters used in rating, Debt/EBITDA and some others. We will use last formula to build a curve of dependence $W A C C\left(l_{1}\right)$.

\subsubsection{Leverage Ratios for Interest on Credit}

$$
\text { Here } l_{2}=k_{d} D / C F
$$

We use again the Modigliani-Miller theorem for case with corporate taxes

$$
V_{L}=V_{0}+D t,
$$

we derive the expression for $W A C C\left(I_{2}\right)$

$$
\begin{aligned}
& \frac{C F}{W A C C}=\frac{C F}{k_{0}}+D t \\
& \frac{1}{W A C C}=\frac{1}{k_{0}}+\frac{l_{2} t}{k_{d}} \\
& W A C C=\frac{k_{0} k_{d}}{k_{d}+t l_{2} k_{0}}
\end{aligned}
$$

This ratio $\left(l_{2}\right)$ can be used to assess of the following parameters used in rating, Interests/EBITDA and some others. We will use last formula to build a curve of dependence $\operatorname{WACC}\left(I_{2}\right)$.

\subsubsection{Leverage Ratios for Debt and Interest on Credit}

$$
\text { Here } l_{3}=D\left(1+k_{d}\right) / C F
$$

Using the Modigliani-Miller theorem for case with corporate taxes

$$
V_{L}=V_{0}+D t,
$$

we derive the expression for $W A C C\left(l_{3}\right)$

$$
\begin{aligned}
& \frac{C F}{W A C C}=\frac{C F}{k_{0}}+D t \\
& \frac{1}{W A C C}=\frac{1}{k_{0}}+\frac{l_{3} t}{1+k_{d}} \\
& W A C C=\frac{k_{0}\left(1+k_{d}\right)}{1+k_{d}+t l_{3} k_{0}}
\end{aligned}
$$

This ratio $\left(l_{3}\right)$ can be used to assess of the following parameters used in rating, Debt + interest/FFO, Debt + interest/EBIT, Debt + interest/EBITDA $(R)$, and some others. We will use last formula to build a curve of dependence $W A C C\left(I_{3}\right)$.

Let us analyze the dependence of company's weighted average cost of capital ( $W A C C$ ) on the leverage ratios with the following data: $k_{0}=12 \% ; k_{d}=6 \% ; t=$ $20 \% ; l_{i}$ runs from 0 up to 10 . The dependence of company's weighted average cost of capital (WACC) on the leverage ratio on debt $l_{1}$ is presented at Figure 5.

The dependence of company's weighted average cost of capital (WACC) on the leverage ratio on interest on credit $l_{2}$ is presented at Figure 6.

The dependence of company's weighted average cost of capital (WACC) on the leverage ratio on debt and interest on credit $l_{3}$ is presented at Figure 7. 


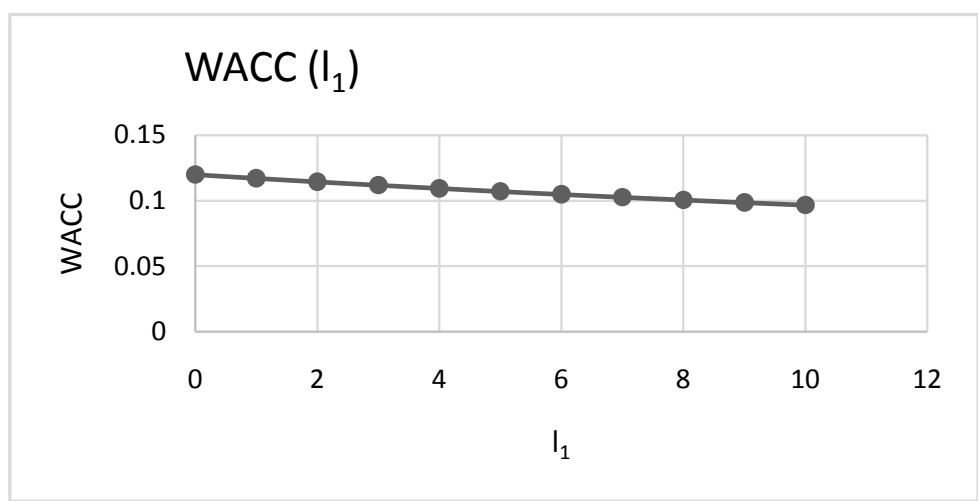

Figure 5. The dependence of company's weighted average cost of capital (WACC) on the leverage ratio on debt $l_{1}$.

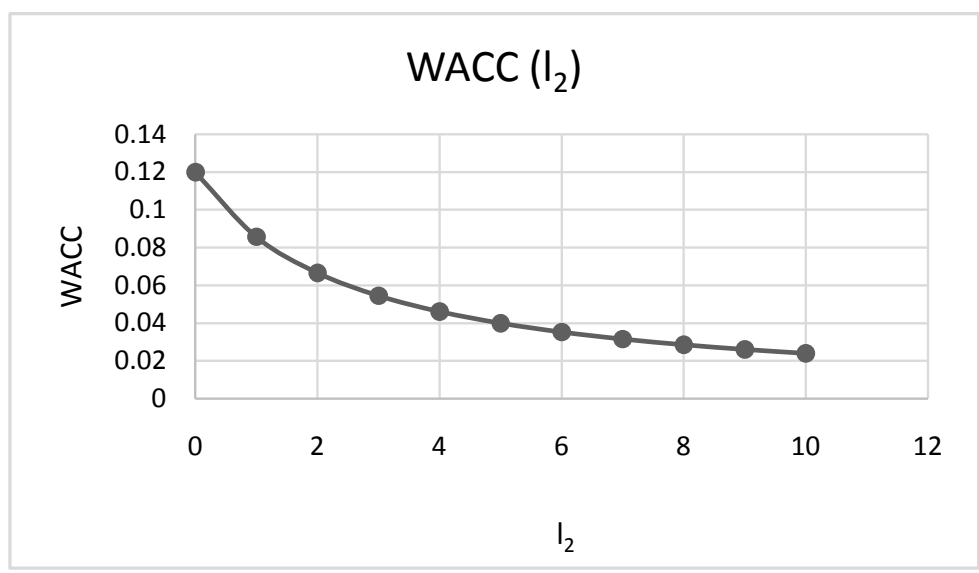

Figure 6. The dependence of company's weighted average cost of capital (WACC) on the leverage ratio on interest on credit $l_{2}$.

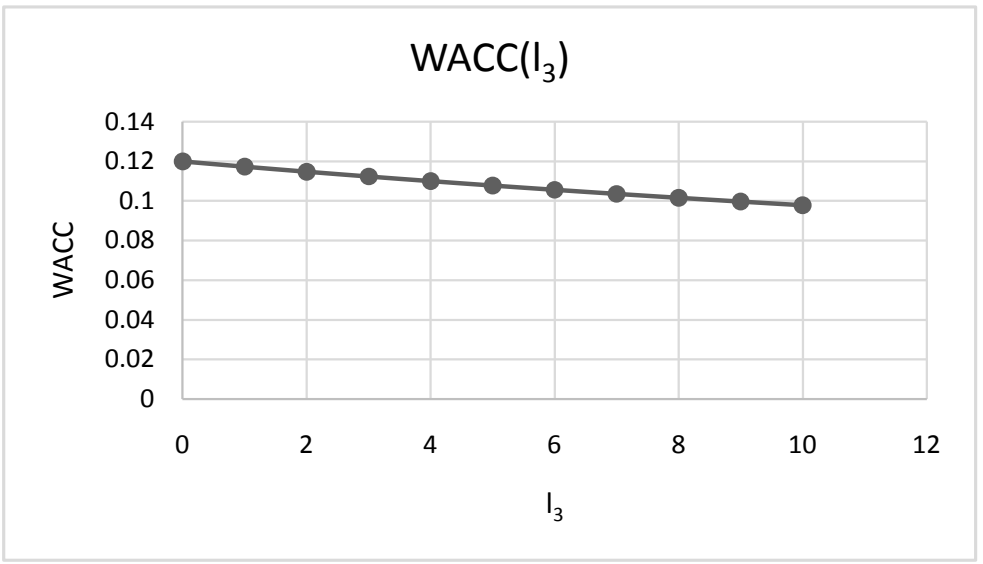

Figure 7. The dependence of company's weighted average cost of capital (WACC) on the leverage ratio on debt and interest on credit $l_{3}$.

The dependence of company's weighted average cost of capital (WACC) on the leverage ratio on debt, $l_{1}$, on interest on credit, $l_{2}$, and on debt and interest on credit, $I_{3}$ simultaneously is presented at Figure 8. 


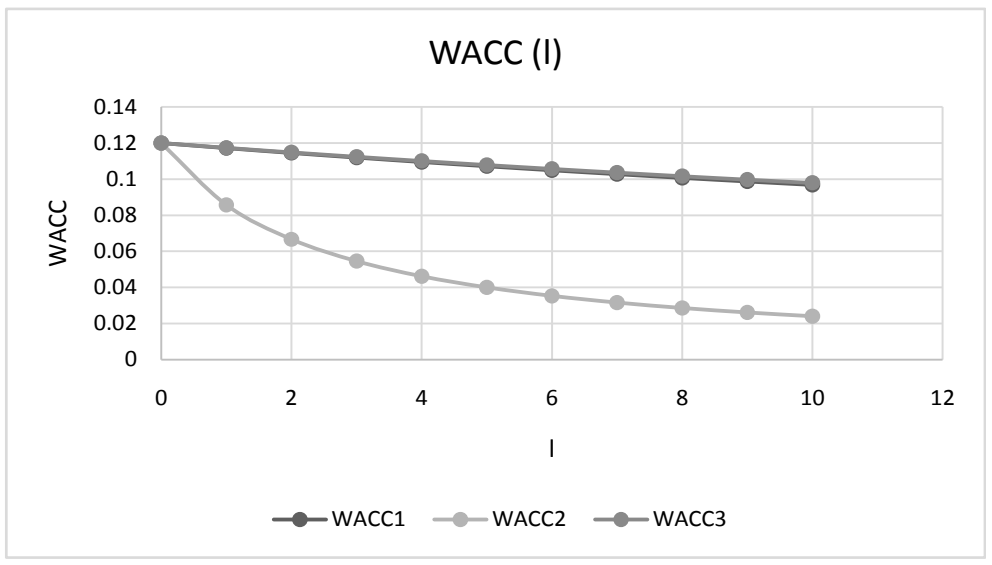

Figure 8. The dependence of company's weighted average cost of capital (WACC) on the leverage ratio on debt, $l_{1}$, on interest on credit, $l_{2}$, and on debt and on interest on credit, $l_{3}$ simultaneously.

Analysis of the dependences of company's weighted average cost of capital (WACC) on the leverage ratio on debt, $l_{1}$, on interest on credit, $l_{2}$, and on debt and interest on credit, $l_{3}$ shows the following: for all leverage ratios weighted average cost of capital (WACC) decreases with leverage ratios. For leverage ratio on debt $I_{1}$ and leverage ratio on debt and interest on credit $l_{3}$ WACC decreases very similar and practically linearly from $k_{0}=12 \%$ at $I_{1,3}=0$ up to $9.7 \%$ at $I_{1,3}=$ 10. For leverage ratio on interest on credit $I_{2} W A C C$ decreases nonlinearly and much faster from $k_{0}=12 \%$ at $l_{2}=0$ up to $2.4 \%$ at $l_{2}=10$.

\section{Method of Evaluation of the Discount Rate}

Let us discuss now the algorithm of valuation of the discount rate, if we know one or a few ratios (coverage or leverage ones). The developed above method allow estimate discount rate with the best accuracy characteristic for used theory of capital structure (perpetuity limit).

\subsection{Using One Ratio}

If one know one ratio (coverage or leverage one) the algorithm of valuation of the discount rate is as following:

1) Determination of the parameter $k_{0}$;

2) Knowing $k_{0}, k_{d}$ and $t$, one builds the curve of dependence WACC $(i)$ or WACC(I);

3) Then, using the known value of coverage ratio $\left(i_{0}\right)$ or leverage ratio $\left(l_{0}\right)$ one finds the value $W A C C\left(i_{0}\right)$ or $W A C C\left(I_{0}\right)$, which represents the discount rate.

\subsection{Using a Few Ratios}

If we know say $m$ values of coverage ratios $\left(i_{j}\right)$ and $n$ values of leverage ratios $\left(I_{k}\right)$ :

1) We find by the above algorithm $m$ values of $W A C C\left(i_{j}\right)$ and $n$ values of $W A C C\left(I_{k}\right)$ first;

2) Then we find the average value of $W A C C$ by the following formula: 


$$
\text { WACC }_{a v}=\frac{1}{m+n}\left[\sum_{j=1}^{m} \operatorname{WACC}\left(i_{j}\right)+\sum_{k=1}^{n} \operatorname{WACC}\left(l_{k}\right)\right] .
$$

This found value $W A C C_{a v}$ should be used when discounting the financial flows in rating.

\section{Conclusion}

In a first part of paper a new approach to rating methodology has been developed, using the perpetuity limit of the modern theory of capital structure-BFO theory-MM theory [1]-[16]. A new approach is based on two key factors: 1) The adequate use of discounting of financial flows virtually not used in existing rating methodologies, 2) The introduction of financial "ratios" into Modigliani-Miller theory [17] [18] [19]. This allows use the powerful tool of this theory in the rating. Below we'll consider the application of the modern theory of capital structure-BFO theory (general case of arbitrary age companies) in rating.

\section{Modification of the BFO Theory (for Companies of Arbitrary Age) for Rating Needs}

We will conduct below the modification of the BFO theory for companies of arbitrary age for rating needs, which proved much more difficult than modification of its (BFO theory) perpetuity limit.

As it turned out, use of the famous BFO formula

$$
\frac{\left[1-(1+\text { WACC })^{-n}\right]}{\text { WACC }}=\frac{\left[1-\left(1+k_{0}\right)^{-n}\right]}{k_{0}\left[1-\omega_{d} T\left(1-\left(1+k_{d}\right)^{-n}\right)\right]}
$$

not possible, since it no longer includes cash flows $C F$ and debt value $D$, and the leverage level $L=D / S$ (in the same sense as it is used in financial management) is included only through the share of leveraged $w_{d}=L /(L+1)$.

To modify the general BFO theory for rating needs, one should return to the initial assumptions under the derivation of the BFO formula.

Modigliani-Miller theorem in case of existing of corporate taxes, generalized by us for the case of finite company age, states [17] [18] [19] that capitalization of leveraged company (using the debt financing), $V_{L}$, is equal to the capitalization of non-leveraged company (which does not use the debt financing), $V_{0}$, increased by the amount of the tax shield for the finite period of time, $T S_{n}$,

$$
V_{L}=V_{0}+T S_{n} \text {. }
$$

where

$$
\text { the capitalization of leveraged company } V_{L}=\frac{C F}{W A C C}\left(1-(1+W A C C)^{-n}\right) \text {; }
$$

the capitalization of non-leveraged company

$$
V_{0}=\frac{C F}{k_{0}}\left(1-\left(1+k_{0}\right)^{-n}\right) ;
$$


and the tax shield for the period of $\mathrm{n}$ years

$$
T S_{n}=t D\left(1-\left(1+k_{d}\right)^{-n}\right) .
$$

Substituting Equations (14)-(16) into Equation (13), we obtain the Equation (17), which will be used by us in the future to modify the BFO theory for the rating needs.

$$
\frac{C F *\left(1-(1+W A C C)^{-n}\right)}{W A C C}=\frac{C F}{K_{0}} *\left(1-\left(1+k_{0}\right)^{-n}\right)+t * D *\left(1-\left(1+k_{d}\right)^{-n}\right)
$$

Below we fulfill the introduction of financial "ratios" into the modern theory of capital structure (Brusov-Filatova-Orekhova (BFO) theory).

As in case of Modigliani-Miller theory above let us consider two kind of rating ratios: coverage ratios and leverage ratios.

\subsection{Coverage Ratios}

We start from the coverage ratios and will consider three kind of coverage ratios: coverage ratios of debt, coverage ratios of interest on the credit and coverage ratios of debt and interest on the credit. Note, that last type of ratios has been introduced by us for the first time for a more complete valuation of the issuer's ability to repay debts and to pay interest thereon.

\subsubsection{Coverage Ratios of Debt}

Let us consider the coverage ratios of debt first.

Dividing the both parts of the Formula (17) by the value of the debt $D$, we enter the debt coverage ratio into the general BFO theory

$$
\begin{gathered}
i_{1}=C F / D \\
\frac{i_{1} *\left(1-(1+W A C C)^{-n}\right)}{W A C C}=\frac{i_{1} *\left(1-\left(1+k_{0}\right)^{-n}\right)}{k_{0}}+t *\left(1-\left(1+k_{d}\right)^{-n}\right) \\
i_{1} * A=i_{1} * B+t * C \\
A=\frac{1-(1+W A C C)^{-n}}{W A C C} ; \\
B=\frac{1-\left(1+k_{0}\right)^{-n}}{k_{0}} ; \\
C=\left(1-\left(1+k_{d}\right)^{-n}\right) ;
\end{gathered}
$$

This ratio $\left(i_{1}\right)$ can be used to assess of the following parameters used in rating, DCF/Debt, FFO/Debt, CFO/Debt, FOCF/Debt and some others. We will use Formula (19) to study the dependence $W A C C\left(i_{1}\right)$ and to build a curve of this dependence.

As example, we will analyze the dependence of the weighted average cost of capital, $W A C C$, on debt coverage ratio $\mathrm{i}_{1}$. We consider the case $k_{0}=8 \% ; k_{d}=4 \%$; $t=20 \% ; i_{1}$ is changed from 1 up to 10 , for two company ages $n=3$ and $n=5$. 
The dependence of company's weighted average cost of capital (WACC) on the coverage ratio on debt $i_{1}$ is shown at Figure 9 and Figure 10.

\subsubsection{The Coverage Ratio on Interest on the Credit}

Let us analyze now the dependence of company's weighted average cost of capital ( $W A C C$ ) on the coverage ratio on interest on the credit $i_{2}$.

Dividing the both parts of the Formula (17) by the value of the interest on the credit $k_{d} D$, enter the coverage ratio on interest on the credit $i_{2}$ into the general BFO theory

$$
\frac{i_{2} *\left(1-(1+W A C C)^{-n}\right)}{W A C C}=\frac{i_{2} *\left(1-\left(1+k_{0}\right)^{-n}\right)}{k_{0}}+\frac{t *\left(1-\left(1+k_{d}\right)^{-n}\right)}{k_{d}}
$$

Here

$$
\begin{gathered}
\frac{C F}{D * k_{d}}=i_{2} \\
i_{2} * A=i_{2} * B+\frac{t * C}{k_{d}}
\end{gathered}
$$

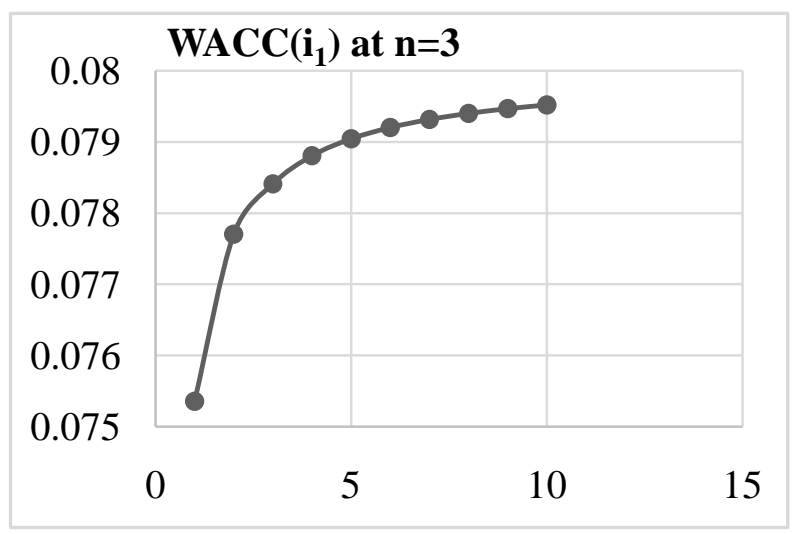

Figure 9. The dependence of company's weighted average cost of capital (WACC) on the coverage ratio on debt $i_{1}$ at $\mathrm{n}=3$.

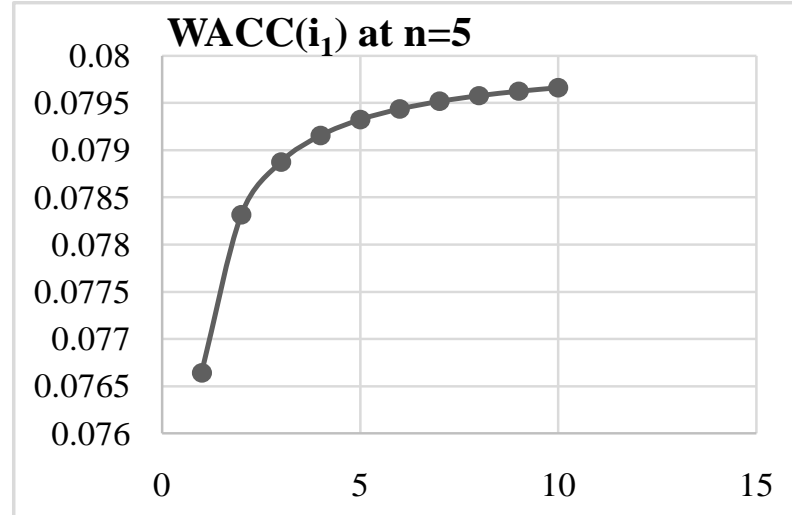

Figure 10. The dependence of company's weighted average cost of capital (WACC) on the coverage ratio on debt $i_{1}$ at $\mathrm{n}=5$. 
The dependences of company's weighted average cost of capital (WACC) on the coverage ratio on interest on the credit $i_{2}$ at company ages $n=3$ and $n=5$ are shown at Figure 11 and Figure 12.

This ratio $\left(i_{2}\right)$ can be used to assess of the following parameters, used in rating, $\mathrm{FFO} /$ cash interest, EBITDA/interest and some others. We will use last formula to build a curve of dependence $W A C C\left(i_{2}\right)$.

\subsubsection{Coverage Ratios of Debt and Interest on the Credit}

Let us now study the dependence of the company's weighted average cost of capital (WACC) on the coverage ratios of debt and interest on the credit simultaneously $\mathrm{i}_{3}$ : this is new ratio, introduced by us for the first time here for a more complete description of the issuer's ability to repay debts and to pay interest thereon.

Dividing the both parts of the Formula (17) by the value of the debt and interest on the credit $\left(1+k_{d}\right) D$, enter the coverage ratio on debt and interest on

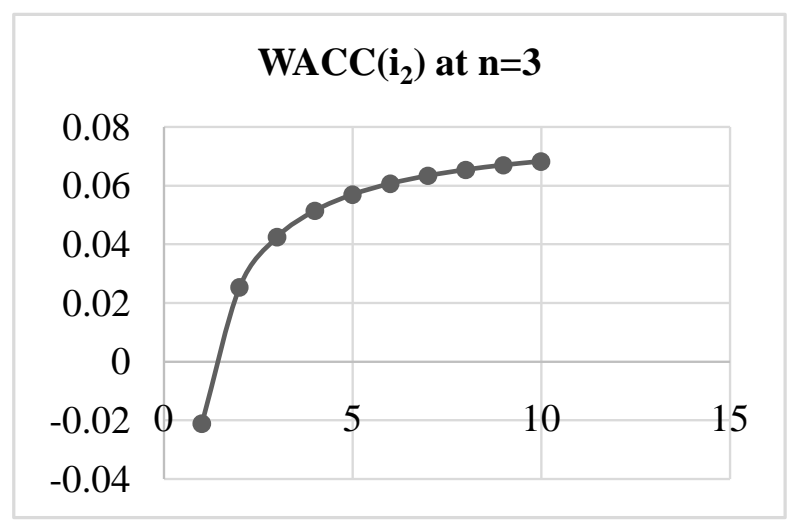

Figure 11. The dependence of company's weighted average cost of capital (WACC) on the coverage ratio on interest on the credit $i_{2}$ at company age $\mathrm{n}=3$.

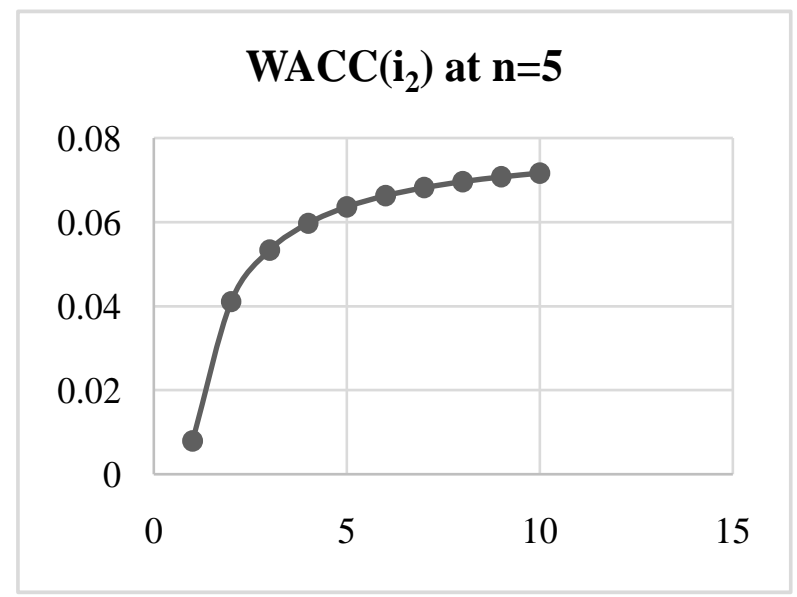

Figure 12. The dependence of company's weighted average cost of capital (WACC) on the coverage ratio on interest on the credit $i_{2}$ at company age $\mathrm{n}=5$. 
the credit $i_{3}$ into the general BFO theory

$$
\begin{gathered}
\frac{C F}{D *\left(1+k_{d}\right)}=i_{3} \\
i_{3} * A=i_{3} * B+\frac{t * C}{1+k_{d}} * i_{3} \\
\frac{i_{3} *\left(1-(1+W A C C)^{-n}\right)}{W A C C}=\frac{i_{3} *\left(1-\left(1+k_{0}\right)^{-n}\right)}{k_{0}}+\frac{t *\left(1-\left(1+k_{d}\right)^{-n}\right)}{1+k_{d}}
\end{gathered}
$$

The dependences of company weighted average cost of capital (WACC) on the coverage ratio on debt and interest on the credit $i_{3}$ at company age $n=3$ and $n=3$ are shown at Figure 13 and Figure 14.

\subsubsection{All Three Coverage Ratios Together}

Consolidated data of dependence of WACC on $i_{1}, i_{2}, i_{3}$, at company age $n=3$ and $n=5$ are shown at Figure 15 and Figure 16.

Below we analyze the Figures 1-16.

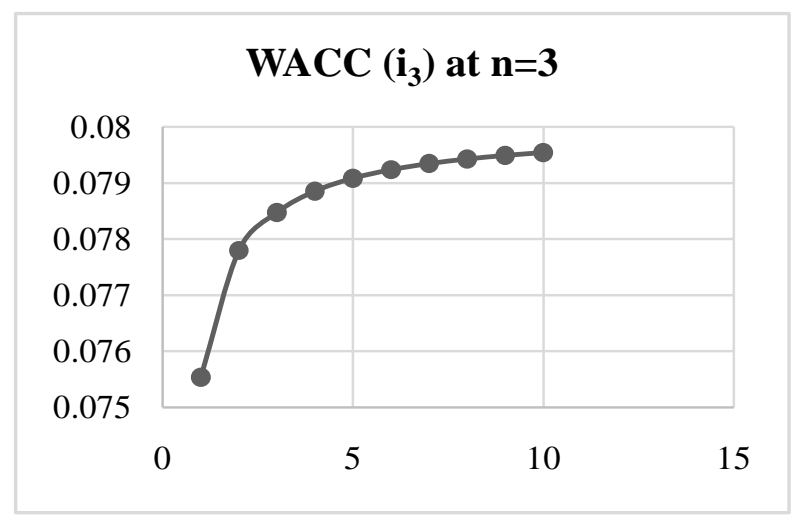

Figure 13. The dependence of company's weighted average cost of capital (WACC) on the coverage ratio on debt and interest on the credit $i_{3}$ at company age $\mathrm{n}=3$.

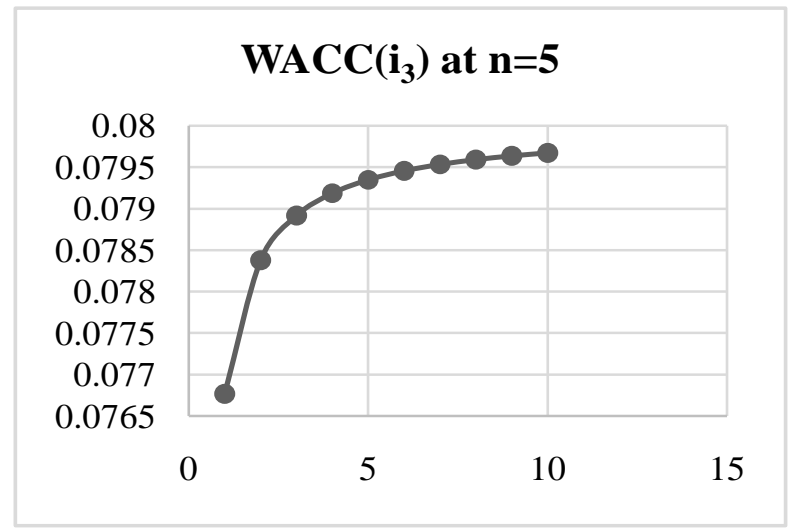

Figure 14. The dependence of company's weighted average cost of capital (WACC) on the coverage ratio on debt and interest on the credit $i_{2}$ at company age $\mathrm{n}=5$. 


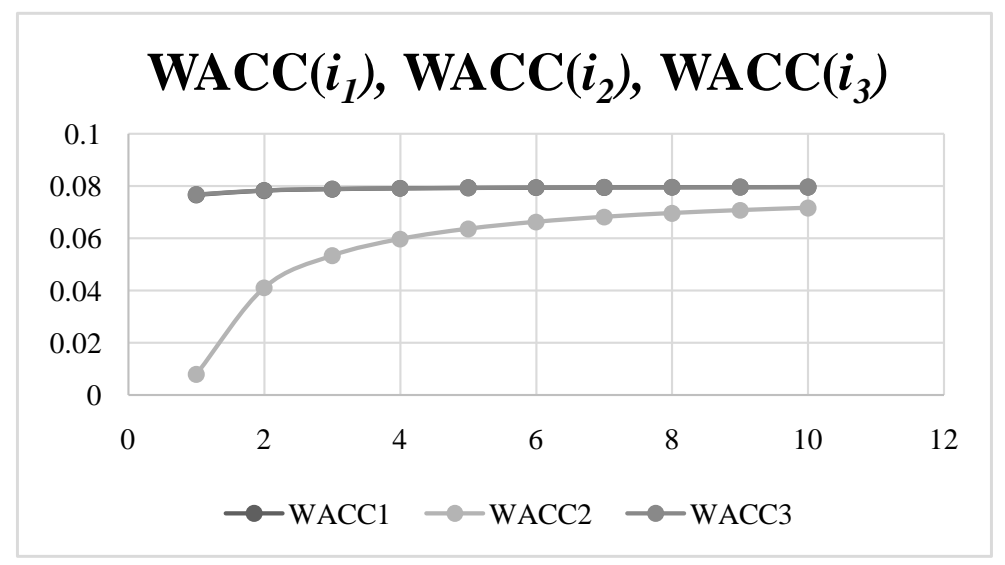

Figure 15. Consolidated data of dependence of WACC on $i_{1}, i_{2}, i_{3}$, at company age $n=3$.

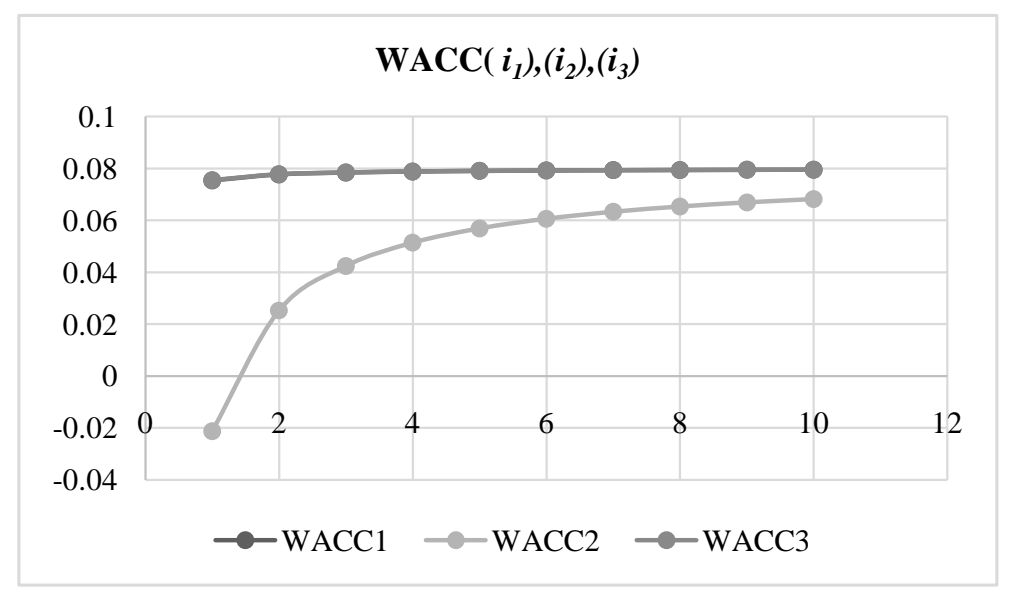

Figure 16. Consolidated data of dependence of WACC on $i_{1}, i_{2}, i_{3}$, at company age $n=5$.

\subsubsection{Analysis and Conclusions}

It is seen from the Figures 1-16 that $W A C C\left(i_{j}\right)$ is increasing function on $i_{j}$ with saturation $W A C C=k_{0}$ at high values of $i_{j}$ Note, that this saturation for companies of finite age is a little bit more gradual than in case of perpetuity companies: in latter case the saturation takes place around $i_{j}$ value of order 1 for ratios $i_{1}$ and $i_{3}$ and of order 4 or 5 for ratios $i_{2}$. In perpetuity case as well as in case of companies of finite age at saturation $W A C C$ reaches the value $k_{0}$ (equity value at zero leverage level). This means that for high values of $i_{j}$ one can choose $k_{0}$ as a discount rate with a very good accuracy in perpetuity case and with a little bit less accuracy in general case (companies of arbitrary ages). Thus the role of parameter $k_{0}$ increases drastically. The method of determination of parameter $k_{0}$ has been developed by Anastasiya Brusova [14]. So, parameter $k_{0}$ is the discount rate for case of high values of $i_{j}$ In case of ratio $i_{2}$ in general case as well as in perpetuity case the saturation of $W A C C\left(i_{2}\right)$ takes place at higher values of $i_{2}$.

In opposite to perpetuity case within BFO theory one could make calculations for companies of arbitrary age because a factor of time presents in this theory. 
Our calculations show that curve $W A C C\left(i_{j}\right)$ for company of higher age lies above this curve for younger company. And with increase of $i_{j}$ value the WACC values for different company ages $\mathrm{n}$ become closer each other.

Note that curves $W A C C\left(i_{1}\right)$ and $W A C C\left(i_{3}\right)$ are very close each other at small enough credit rates, but difference between them will become bigger at higher values of credit rates.

Curve $W A C C\left(i_{2}\right)$ turns out to be enough different from $W A C C\left(i_{1}\right)$ and curves $W A C C\left(i_{3}\right)$.

\subsection{Leverage Ratios}

\subsubsection{Leverage Ratios for Debt}

Dividing the both parts of the Formula (17) by the income value for one period $C F$, we enter the leverage ratios $l_{1}$ for debt into the general BFO theory

$$
\begin{gathered}
\frac{1-(1+W A C C)^{-n}}{W A C C}-\frac{1-\left(1+K_{0}\right)^{-n}}{K_{0}}-t *\left[1-\left(1+K_{d}\right)^{-n}\right] * l_{1}=0, \\
\text { Here } l_{1}=\frac{D}{C F} .
\end{gathered}
$$

Remind, that here $W A C C$ is the weighted average cost of capital of the company, $l_{1}$-the leverage ratios $l_{1}$ for debt, $t$ is the tax on profit rate for organizations $(t=20 \%), k_{0}$-equity cost of financially-independent company, $k_{d}$ is the debt capital cost; $n$ is the company age, $C F$-income value for one period; $D$ debt capital value.

The ratio $\left(l_{2}\right)$ can be used to assess of the following parameters used in rating, Interests/EBITDA and some others.

By use the above equation we get the following results, representing in Figure 17 for company age $n=3$ and in Figure 18 for company age $n=5$.

\subsubsection{Leverage Ratios for Interest on Credit}

The dependence of company weighted average cost of capital (WACC) on leverage ratios on interests on credit $l_{2}$ is described within BFO theory by the following formula:

$$
\frac{1-(1+W A C C)^{-n}}{W A C C}-\frac{1-\left(1+K_{0}\right)^{-n}}{K_{0}}-\frac{t * l_{2} *\left[1-\left(1+K_{d}\right)^{-n}\right]}{K_{d}}=0,
$$

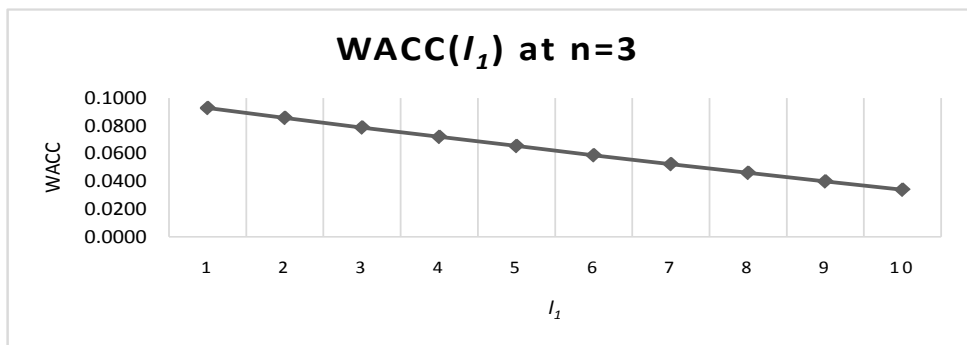

Figure 17. The dependence of company weighted average cost of capital (WACC) on debt leverage ratio at $\mathrm{n}=3$. 
Here $l_{2}=\frac{K_{d} * D}{C F}$.

Using it, we find the dependence $W A C C\left(l_{2}\right)$ at company ages $n=3$ and $n=5$.

This ratio $I_{2}$ can be used to assess of the following parameters used in rating, Interests/EBITDA and some others (Figure 19, Figure 20).

\subsubsection{Leverage Ratios on Debt and Interests on Credit}

The dependence of company weighted average cost of capital (WACC) on leverage ratios on debt and interests on credit $l_{3}$ is described within BFO theory by the following formula:

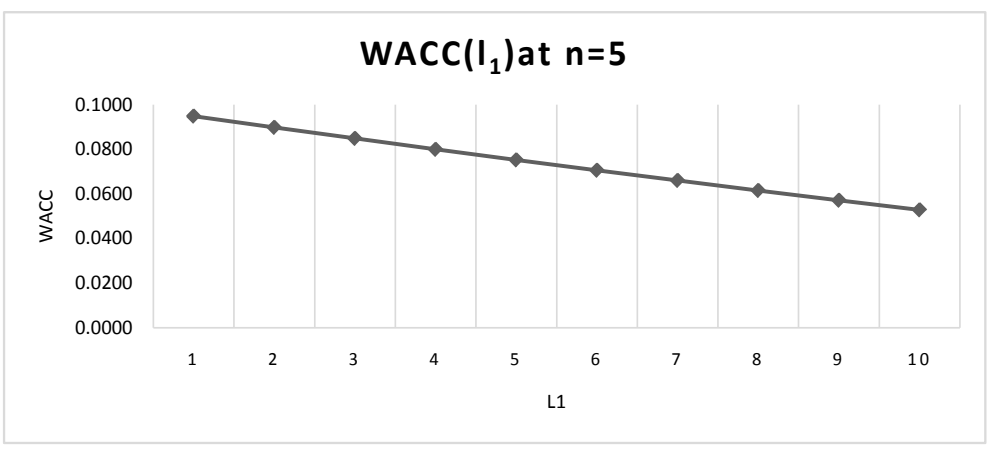

Figure 18. The dependence of company weighted average cost of capital WACC on debt leverage ratios at $\mathrm{n}=5$.

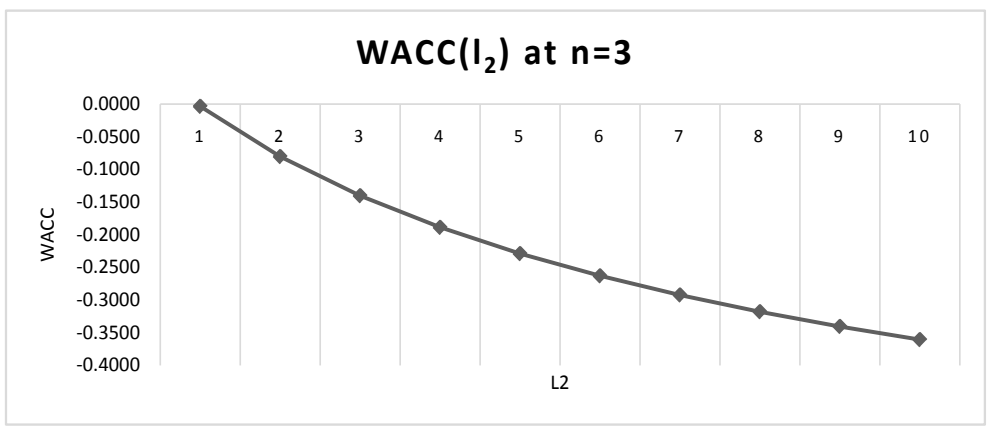

Figure 19. The dependence of company weighted average cost of capital (WACC) on leverage ratio of interests on credit at company age $n=3$.

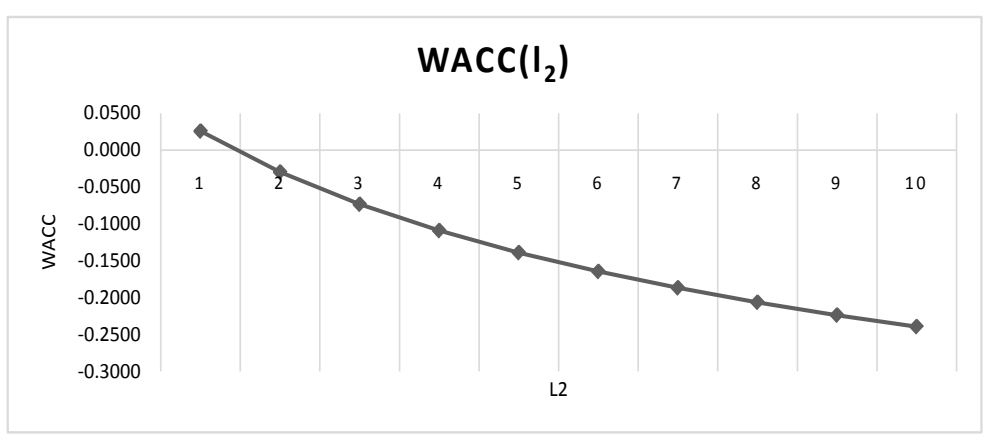

Figure 20. The dependence of company weighted average cost of capital (WACC) on leverage ratio of interests on credit at company age $n=5$. 


$$
\begin{gathered}
\frac{1-(1+W A C C)^{-n}}{\text { WACC }}-\frac{1-\left(1+K_{0}\right)^{-n}}{K_{0}}-\frac{t * l_{3} *\left[1-\left(1+K_{d}\right)^{-n}\right]}{K_{d}+1}=0 \\
\text { Here } l_{3}=\frac{\left(K_{d}+1\right) * D}{C F} .
\end{gathered}
$$

The ratio $I_{3}$ can be used to assess of the following parameters used in rating, Debt + interest/FFO, Debt + interest/EBIT, Debt + interest/EBITDA $(R)$, and some others.

Using it, we find the dependence $W A C C\left(l_{3}\right)$ at company ages $n=3$ and $n=5$ (Figure 21, Figure 22).

Below we represent the consolidated data of dependence of WACC on $l_{1}, l_{2}, l_{3}$, at company age $n=3$ and $n=5$ (Figure 23, Figure 24).

\subsubsection{Analysis and Conclusions}

It is seen from the Figures 17-24 that $W A C C\left(l_{j}\right)$ is decreasing function on $l_{j}$. $W A C C$ decreases from value of $k_{0}$ (equity value at zero leverage level) practically linearly for $W A C C\left(l_{1}\right)$ and $W A C C\left(l_{3}\right)$ and with higher speed for $W A C C\left(l_{2}\right)$. In opposite to perpetuity case within BFO theory one could make calculations for companies of arbitrary age because a factor of time presents in this theory. Our calculations show that curve $W A C C\left(I_{i}\right)$ for company of higher age lies above this curve for younger company.

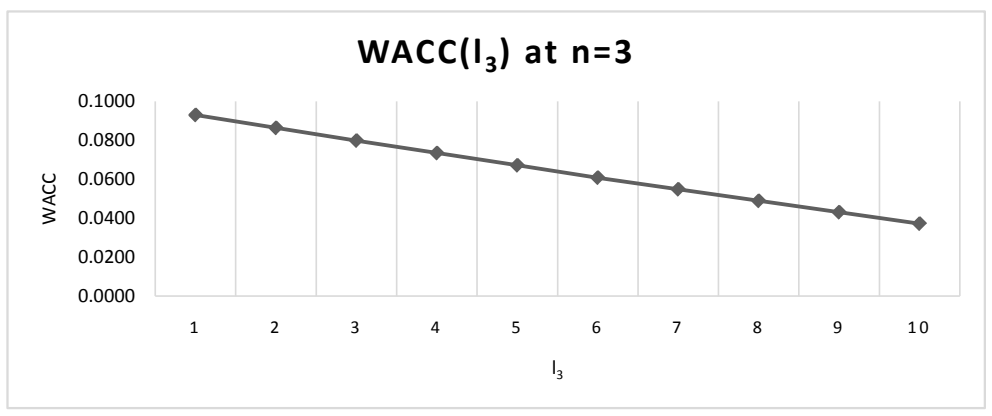

Figure 21. The dependence of company weighted average cost of capital (WACC) on leverage ratio on debt and interests on credit at company age $n$ $=3$.

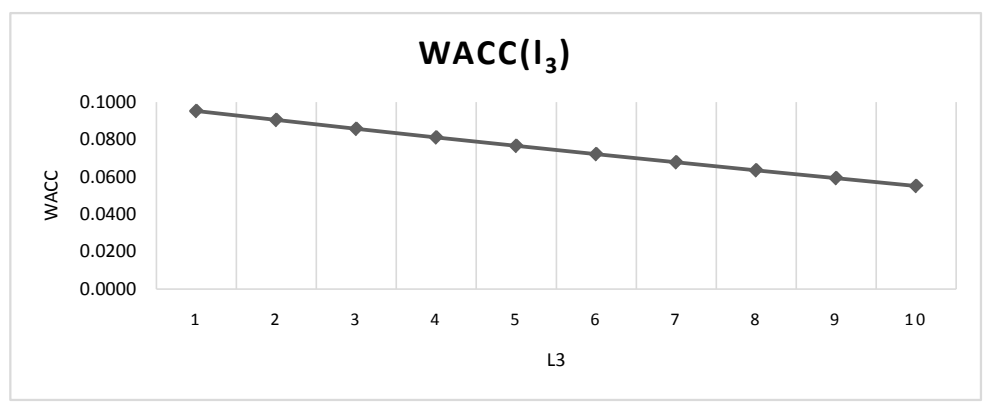

Figure 22. The dependence of company weighted average cost of capital (WACC) on leverage ratio of debt and interests on credit at company age $\mathrm{n}$ $=5$. 


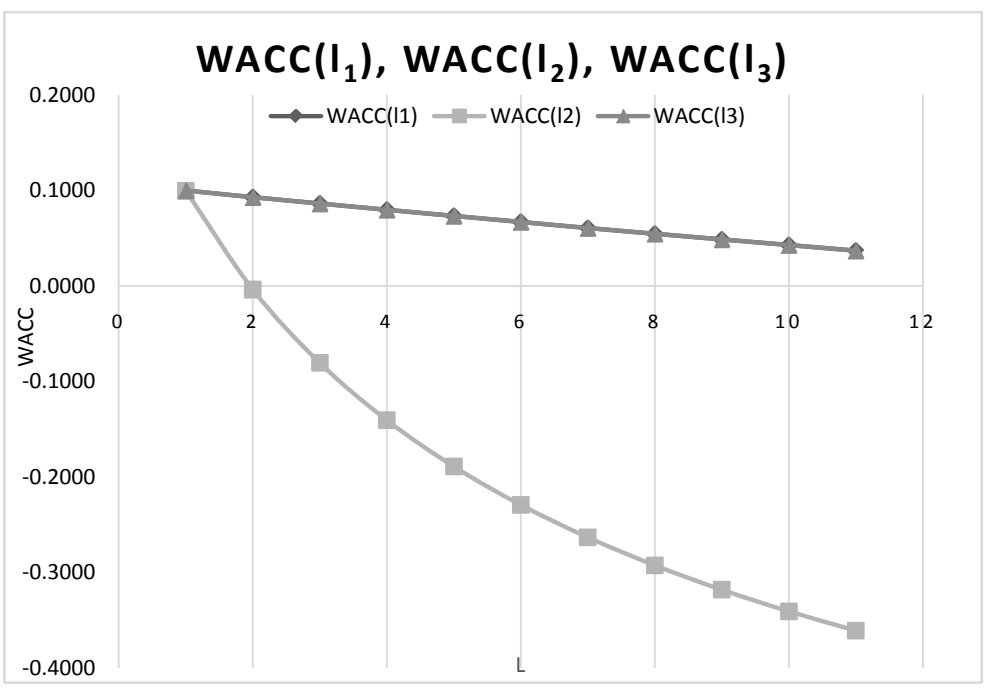

Figure 23. Consolidated data of dependence of WACC on $l_{1}, l_{2}, l_{3}$, at company age $n=3$.

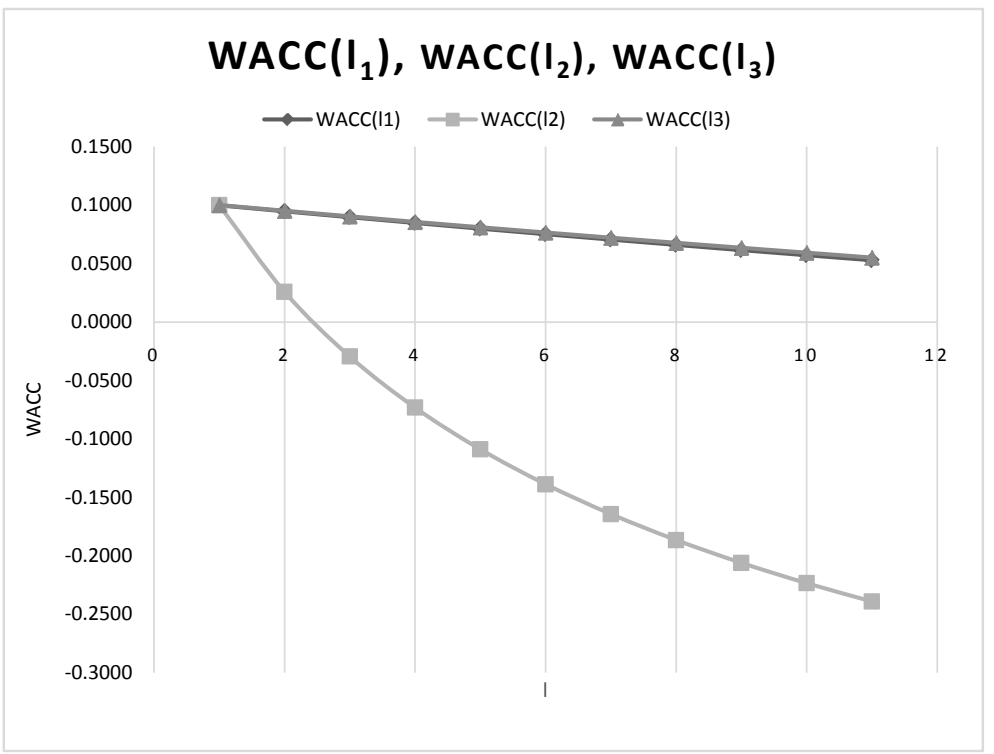

Figure 24. Consolidated data of dependence of WACC on $I_{1}, l_{2}, l_{3}$, at company age $n=5$.

Note that curves $W A C C\left(l_{1}\right)$ and $W A C C\left(l_{3}\right)$ are very close each other at small enough credit rates, but difference between them will become bigger at higher values of credit rates.

Curve $W A C C\left(l_{2}\right)$ turns out to be enough different from $W A C C\left(l_{1}\right)$ and curves $W A C C\left(l_{3}\right)$.

\section{Conclusions}

The paper is devoted to application of Brusov-Filatova-Orekhova theory (BFO theory) [1]-[16] and Modigliani-Miller theory (MM theory) [17] [18] [19] in rating. A serious modification of both theories in order to use them in rating 
procedure has been required. The use of BFO theory allows applying obtained results for real economics, where all companies have finite lifetime, introduce a factor of time into theory, estimate the creditworthiness of companies of arbitrary age (or arbitrary lifetime), introduce discounting of the financial flows, using the correct discount rate etc. Use of the tools of well developed theories in rating opens completely new horizons in the rating industry, which could go from the mainly use of qualitative methods of the evaluation of the creditworthiness of issuers to a predominantly quantitative evaluation methods that will certainly enhance the quality and correctness of the rating.

Currently, rating agencies use financial ratios just directly, while the new methodology will allow (knowing the values of these "ratios" (and parameter $k_{0}$ )) determine the correct values of discount rates (WACC and $k_{e}$ ) that should be used when discounting the various financial flows, both in terms of their timing and forecasting.

All these create a new base for rating methodologies.

\section{Acknowledgements}

The reported study was funded by RFBR according to the research project No. 17-06-00251A.

\section{References}

[1] Brusov, P., Filatova, T., Orehova, N. and Eskindarov, M. (2015) Modern Corporate Finance, Investment and Taxation. Springer International Publishing, Berlin, 1-368. https://doi.org/10.1007/978-3-319-14732-1

[2] Brusov, P., Filatova, T., Orehova, N. and Brusova, A. (2011) Weighted Average Cost of Capital in the Theory of Modigliani-Miller, Modified for a Finite Life-Time Company. Applied Financial Economics, 21, 815-824. https://doi.org/10.1080/09603107.2010.537635

[3] Brusov, P., Filatova, P. and Orekhova, N. (2013) Absence of an Optimal Capital Structure in the Famous Tradeoff Theory! Journal of Reviews on Global Economics, 2, 94-116.

[4] Brusov, P., Filatova, P. and Orekhova, N. (2014) Mechanism of Formation of the Company Optimal Capital Structure, Different from Suggested by Trade off Theory. Cogent Economics \& Finance, 2, 1-13. https://doi.org/10.1080/23322039.2014.946150

[5] Brusov, P., Filatova, T., Orehova, N., et al. (2011) From Modigliani-Miller to General Theory of Capital Cost and Capital Structure of the Company. Research Journal of Economics, Business and ICT, 2, 16-21.

[6] Brusov, P., Filatova, T., Eskindarov, M. and Orehova, N. (2012) Influence of Debt Financing on the Effectiveness of the Finite Duration Investment Project. Applied Financial Economics, 22, 1043-1052. https://doi.org/10.1080/09603107.2011.637893

[7] Brusov, P., Filatova, T., Orehova, N., et al (2011) Influence of Debt Financing on the Effectiveness of the Investment Project within the Modigliani-Miller Theory. Research Journal of Economics, Business and ICT, 2, 11-15.

[8] Brusov, P., Filatova, T., Eskindarov, M. and Orehova, N. (2012) Hidden Global Causes of the Global Financial Crisis. Journal of Reviews on Global Economics, 1, 
106-111. https://doi.org/10.6000/1929-7092.2012.01.9

[9] Brusov, P., Filatova, T. and Orekhova, N. (2013) Absence of an Optimal Capital Structure in the Famous Tradeoff Theory! Journal of Reviews on Global Economics, 2, 94-116.

[10] Brusov, P.N. and Filatova, T.V. (2011) From Modigliani-Miller to General Theory of Capital Cost and Capital Structure of the Company. Finance and Credit, 435, 2-8.

[11] Brusov, P., Filatova, T., Orekhova, N., Brusov, P. and Brusova, A. (2012) Modern Approach to Dividend Policy of Company. Finance and Credit, 18.

[12] Brusov, P., Filatova, T., Orehova, N., Brusov, P.P. and Brusova, N. (2011) From Modigliani-Miller to General Theory of Capital Cost and Capital Structure of the Company. Research Journal of Economics, Business and ICT, 2, 16-21.

[13] Brusov, P., Filatova, T. and Orehova, N. (2014) Inflation in Brusov-Filatova-Orekhova Theory and in Its Perpetuity Limit-Modigliani-Miller Theory. Journal of Reviews on Global Economics, 3, 175-185. https://doi.org/10.6000/1929-7092.2014.03.13

[14] Brusova, A. (2011) A Comparison of the Three Methods of Estimation of Weighted Average Cost of Capital and Equity Cost of Company. Financial Analysis: Problems and Solutions, 34, 36-42.

[15] Brusov, P., Filatova, T. and Orehova, N. (2013) A Qualitatively New Effect in Corporative Finance: Abnormal Dependence of Cost of Equity of Company on Leverage. Journal of Reviews on Global Economics, 2, 183-193.

[16] Filatova, T., Orehova, N. and Brusova, A. (2008) Weighted Average Cost of Capital in the Theory of Modigliani-Miller, Modified for a Finite Life-Time Company. Bulletin of the $F U, 48,68-77$.

[17] Modigliani, F. and Miller, M. (1958) The Cost of Capital, Corporate Finance, and the Theory of Investment. American Economic Review, 48, 261-297.

[18] Modigliani, F. and Miller, M. (1963) Corporate Income Taxes and the Cost of Capital: A Correction. American Economic Review, 53, 147-175.

[19] Modigliani, F. and Miller, M. (1966) Some Estimates of the Cost of Capital to the Electric Utility Industry 1954-1957. American Economic Review, 56, 333-391. 